\title{
HISTÓRIA, ESTRATÉGIA E DESENVOLVIMENTO: PARA UMA GEOPOLÍTICA DO CAPITALISMO
}

FIORI, José Luís. História, Estratégia e Desenvolvimento: para uma geopolítica do capitalismo. Rio de Janeiro: Boitempo, 2014. 277p.

Ricardo Zortéa Vieira'

Devemos em primeiro lugar a Thomas $\mathrm{Kuhn}^{2}$ a contestação da ideia de verdade científica universal, objetiva e permanente. Essas contribuições do epistemólogo ajudam, para um olhar realista, enxergar a relação estreita entre os paradigmas de conhecimento e as estruturas de poder. Podemos entender, assim, que os paradigmas científicos de que Kuhn fala se constroem em grande medida como legitimadores dos poderes em ascensão e solucionadores de seus problemas. Ao mesmo tempo, a própria expansão desses poderes faz convergir as previsões das teorias para a realidade observada, ajudando a torna-las "verdadeiras". Inversamente, grandes modificações no campo do poder refletem-se no campo do conhecimento, desvelando a divergência entre o "paradigma" aceito e a realidade. Tais modificações, se por um lado causam grandes incertezas, por outro criam uma janela que permite a inovação e o avanço no próprio conhecimento. E o tamanho da inovação possível depende do tamanho da janela, que por sua vez é dado pela profundidade do paradigma em crise, derivada das próprias alterações subjacentes nos tendões do poder.

É comum dizer hoje que o sistema internacional vive uma crise de paradigmas. Para Wallerstein ${ }^{3}$, essa crise é a da "geocultura" do sistema -mundo, identificada com o liberalismo de centro surgido no século XIX e

Graduado em Ciências sociais pela Universidade Federal do Paraná. Mestre e Doutorando em Economia Política Internacional pela UFRJ. Membro do Grupo de Pesquisa Poder Global e a Geopolítica do Capitalismo. E-mail: ricardozortea@hotmail.com

Kuhn, T.S. A Estrutura das Revoluções Científicas. São Paulo: Perspectiva, 2000.

Wallerstein, I. The Modern World System IV: Centrist Liberalism Triumphant. Los Angeles, Berkley \& Londres: University of California Press, 20 I I \& Impensar a Ciência Social: Os Limites dos Paradigmas do Século XIX. Aparecida: Editora Ideias \& Letras, 2006. 
que trouxe em seu bojo as próprias ciências sociais modernas, junto com suas principais vertentes teóricas, formadas naquele período. Para os interessados em pensar o mundo e que não são diretamente filiados aos poderes dominantes dentro do sistema, é especialmente dolorosa a perda de vigor de duas dessas correntes: A Marxista e a Weberiana. Ambas surgiram e se consolidaram como espécies de críticas internas formuladas por dois alemães ao núcleo epistêmico do sistema, a tradição do empirismo liberal anglo-saxão que remonta suas origens à Revolução Científica com Bacon e Hobbes, e adquiriu forma com Locke, Newton, Smith, Bentham e outros. E ambas ultrapassaram o campo teórico e inspiraram utopias, especialmente atrativas na periferia do sistema, da revolução socialista no primeiro caso, e da modernização e racionalização, no segundo. Hoje, todavia, tanto as grandes "vertentes críticas" quanto as suas "utopias" se converteram em versões deformadas delas mesmas, sendo animadas por raciocínios e soluções rígidas, incapazes de responder aos grandes problemas que se colocam nesse começo de século ${ }^{4}$.

A resposta dos intelectuais a crise paradigmática, principalmente na periferia, passou de um lado pela reafirmação cega das velhas certezas, e por outro por um cada vez maior sentimento de desamparo e saudosismo epistêmico, teórico e político. Uma terceira trilha, contudo, foi tomada por José Luís Fiori, que a demonstra no seu novo livro, "História, Estratégia e Desenvolvimento: Para uma Geopolítica do Capitalismo". O primeiro passo desse caminho foi, como fez Maquiavel quanto confrontado com as contradições do "grande paradigma" católico no Século XVI, aproveitar a própria intensidade da crise como forma de superá-la. E nesse caso, assim como no de Maquiavel, a intensidade da crise permite olhar profundamente para a essência, não só do poder correntemente dominante e em transformação, mas do poder em si, e assim propor uma nova interpretação metafísica dessa relação, para em seguida a tornar base de um novo programa de pesquisas.

Para Fiori, o poder é uma relação assimétrica fundamental, ou seja, que não conhece precedente, não segue nenhuma lógica a não ser aquela a ele inerente, e nunca é interrompido ou suspenso. Dado o seu caráter assimé-

Sintomas dessa esclerose ocorrem a olhos vistos no radicalismo dos pequenos partidos da extrema esquerda, sem atratividade ou projetos concretos de poder, e no ativismo judiciário que hoje domina as manchetes e é tributário, consciente ou não, de um certo ramo weberiano brasileiro que começa com Faoro e Hollanda e hoje é representado principalmente por DaMatta. 
trico e fundamental, o poder é sempre competitivo. Ao mesmo tempo, essa competição, que criaria uma tendência à autofagia ou a entropia da própria relação se mantida restrita em dois polos, torna o poder essencialmente expansivo na direção de um terceiro polo, que provê tanto a fronteura de expansão quanto a pressão necessária à sua manutenção. Dialeticamente, esse terceiro polo torna, assim, o poder uma relação triangular e limitada, nunca universal ${ }^{5}$.

Tanto Marx quanto Weber enxergavam e entendiam o poder. $\mathrm{O}$ que diferencia a perspectiva de Fiori dos dois teóricos clássicos e das tradições que com eles se iniciaram é que na sua interpretação, o poder é um ente fundamental e seguidor apenas de si mesmo, não se confundindo com nenhuma de suas dimensões ou características particulares: Nesse sentido, ele não se identifica com um capital único e desterritorializado cujas contradições apontam para a revolução, e nem se reduz em última instância à dominação "burocrático-legal" que tende a prevalecer sobre a tradição e o misticismo. Consequentemente, Fiori retira do poder, ao contrário dos clássicos, a capacidade de informar uma grande teleologia histórica: O poder "em geral", na sua visão, só pode dizer que vai se acumular, e os poderes concretos são sempre limitados e particulares, e portanto suas crenças, objetivos e caminhos não podem inspirar nenhuma utopia verdadeiramente universal.

A partir da referência colocada pela sua metafísica do poder, Fiori passa à análise histórica. Nela, propõe que a acumulação de riqueza é derivada da condensação das relações de poder na forma de poderes territoriais, com a sua necessidade específica de defesa de fronteiras. Dado o caráter expansivo do poder, tal defesa só é viável através da manutenção de um ímpeto conquistador, que se transmite para a dimensão material através da tributação e da moeda. São esses dois instrumentos que, como sustentáculos econômicos da guerra e da expansão, foram os responsáveis históricos pelo aumento da produtividade e da inovação ${ }^{6}$.

Em um plano histórico, essa estrutura pode se manifestar na relação de uma autoridade central ou soberano com seu público, que se projeta na direção de um Estado estrangeiro. O poder externo serve como uma ameaça que mantém a autoridade interna, e como fonte de expansão que confere a essa mesma autoridade capacidade de satisfazer ou manipular os seus súditos ou cidadãos.

6 estudo da tributação e a moeda, e posteriormente a dívida pública, como elos que ligam o poder à riqueza, e em última análise a dinamiza, foi historicamente desenvolvido em pesquisas conduzidas principalmente pelo prof. Maurício Metri, da UFRJ. Ver: Metri, M. Poder, Riqueza e Moeda na Europa Medieval: A Preeminência Naval, Mercantil e Monetária da Sereníssima República de Veneza nos Séculos XIII e XV. Rio de Janeiro: Editora FGV, 20 I 4. 
A lógica da extração material seguida de conquista esteve por trás de todos os grandes impérios da História. Mas na Europa a partir do século XII, as guerras religiosas, as rebeliões camponesas e a pressão geopolítica intensiva levaram a um modo de articulação original entre os poderes territoriais e seus sistemas econômicos, que culminou nos séculos XVII e XVIII na criação das chamadas economias, ou Blocos, Nacionais: Espaços reservados à exploração monopólica dos capitais associados ao Estado territorial através da sua moeda, da sua dívida pública e do seu sistema bancário e creditício, e que se tornaram financiadores e sócios privilegiados de sua expansão ${ }^{7}$.

A categoria de Bloco Nacional é central porque permite entender como o objetivo da acumulação de capital se impôs no moderno sistema mundial, que para Fiori é interestatal e capitalista: Esse movimento se deveu não à força dos mercadores ou dos capitalistas, e da sua racionalidade específica, mas da sua simbiose com o poder territorial, que lhe fornece a proteção, o arcabouço institucional que permite a conversão de um espaço em plataforma de acumulação, e as posições monopólicas que os libertam da concorrência compressora dos lucros ${ }^{8}$. Assim, não se pode falar, nesse sistema, de capital em geral, mas de capitais nacionais, e não de um capitalismo único, mas de capitalismos nacionais que em competição garantem a expansão geral do próprio sistema, através da incorporação contínua de espaços econômicos exteriores, pelo movimento de conquista dos seus respectivos Estados.

Inversamente, a acumulação de capital se tornou essencial para qualquer projeto de ascensão estatal dentro do sistema. Mas sob esse prisma, o capital é um instrumento, ainda que vital, de um poder concreto e específico. Não tem portanto uma dinâmica própria e autônoma que seja capaz de demarcar alguma grande tendência sistêmica (ou, como quer Wallerstein, de fim do próprio sistema). Além disso, do ponto de vista do poder concreto, o que

Esses elementos se articularam sob a forma de explosões expansivas do próprio sistema interestatal, com uma primeira ocorrendo entre I I 50 e I 350 ou I450, e uma segunda partindo daí e se estendendo até I650. Posteriormente, a Inglaterra durante a Revolução Financeira, que se consolida entre os séculos XVII e XVIII, logra articular a primeira economia nacional, a partir do protótipo holandês.

8 Aqui fica clara a incorporação na perspectiva do autor do conceito de capitalismo de Fernand Braudel, para quem esse sistema se identifica com os lucros extraordinários que são em última análise incompatíveis com o livre mercado, e só possíveis através da articulação do capitalista com o poder político. Mas ao contrário de Braudel, Fiori busca demonstrar como a origem dessa articulação está na guerra e na geopolítica, que fazem o poder extrair de dentro de uma economia mundo reticular espaços econômicos internamente coerentes e relativamente separados do resto da rede de trocas e finanças, a partir do Longo Século XVI. 
interessa em última análise não é a acumulação de capital ou o crescimento econômico em si, mas a sua utilidade dentro de uma determinada estratégia expansiva, sempre fundamentada no espaço e na guerra, portanto de natureza geopolítica. Daí não haver, na perspectiva articulada em História, Estratégia e Desenvolvimento, um protagonismo natural de nenhum setor econômico, seja primário, manufatureiro, de serviços, ou outro. Por consequência, também não existe uma clivagem dual e intransponível no sistema entre um centro e uma periferia, e nenhum veredicto definitivo sobre os destinos de países ou continentes a partir de setores produtivos sobre os quais suas economias se articulam ou historicamente se articularam ${ }^{9}$.

A relação de hierarquia entre acumulação de poder e acumulação de riqueza aqui elaborada impacta no entendimento tanto dos movimentos do topo do sistema, principalmente na questão da hegemonia, quanto na base, no problema dos desenvolvimentos nacionais. Na primeira, a hegemonia é vista como um fenômeno dos séculos XIX e XX, quando, ao contrário do florim holandês, a libra e depois o dólar se converteram em moedas globais. Isso, contudo, não rompeu a sua filiação com os poderes territoriais de Grã-Bretanha e Estados Unidos, respectivamente, nem seu papel de instrumentos das estratégias expansivas desses países. O papel das moedas mundiais, e dos outros elementos constitutivos da condição hegemônica, nunca foi, assim, o de garantir a estabilidade sistêmica, mas justamente o oposto, ao viabilizar o avanço agressivo do poder hegemônico, que só é parado pelas reações opostas das demais Grandes Potências.

Se a hegemonia não é estabilizadora, o desenvolvimento econômico, segundo a perspectiva de Fiori, não é produto de capitalistas, burguesias "conquistadoras" ou políticas macroeconômicas derivadas das melhores teorias, mas sim como parte constitutiva de estratégias focadas na defesa e na preparação para a guerra. A origem de tais estratégias é sempre um sentimento de cerco e de ameaça, criado por um passado de rebeliões, guerras civis e invasões, em seu turno manifestações das pressões, internas e externas, que existem e se condensam em determinados momentos históricos nos tabuleiros geopolíticos altamente competitivos. $\mathrm{O}$ foco da estratégia passa dessa forma sempre pela defesa e pela preparação para a

O que não é, obviamente, um endosso a políticas primário-exportadoras. Fiori lembra que a indústria foi e segue sendo um setor estratégico para o poder dos Estados, assim como as finanças, a ciência e a tecnologia. 
guerra, acompanhado de uma visão instrumental do campo da economia. A instrumentalização da economia pela estratégia leva sempre ao desrespeito crônico às regras da concorrência no mercado e aos paradigmas de boa gestão econômico-financeira. Esse fato historicamente conviveu com a manutenção ou ampliação, pelos países que se desenvolveram aceleradamente, da sua credibilidade fiscal e creditícia, e de sua capacidade de endividamento, que se tornou fundamento de seu poder. Da mesma forma que a incapacidade de se endividar e tributar se converteram em limites à ascensão dos países da base do sistema, em uma outra forma de "chute à escada", por assim dizer"

De modo talvez surpreendente para aqueles que entendem os problemas e a inserção internacional da América Latina apenas pelo prisma econômico, essa mesma lógica do desenvolvimento puxado pela geopolítica e pelo poder se reproduziu no nosso continente. Principalmente no seu tabuleiro interestatal mais competitivo, o Cone Sul, que testemunhou desde 1860 dois milagres econômicos em sequencia, o Argentino e o Brasileiro. No primeiro caso, o país chegou à liderança do crescimento mundial, originado de uma estratégia expansiva formulada por uma elite civil, militar e intelectual, e com forte proximidade ao poder (e ao financiamento) inglês. O projeto se esgotou nos anos 1940, sendo sua renovação peronista bloqueada pelos EUA, Brasil e uma parte da própria elite argentina. Antes disso, todavia, o milagre argentino provocou reação igual e contrária no Brasil, a partir de um diagnóstico, por uma elite civil e militar conservadora, de deterioração na posição brasileira na bacia do Prata e de cerco pelos vizinhos hispânicos ${ }^{11}$.

Entre os anos 1930 e 1970, essa elite estaria por trás de um movimento que uniu centralização política, reaparelhamento das Forças Armadas e industrialização, acabando por tornar o Brasil a maior economia latino-americana. Como no caso Argentino, o expansionismo brasileiro se baseou em uma aliança com uma potência anglo-saxã, dessa vez os EUA. O projeto expansivo, e a aliança, foram mantidas até o governo Geisel, que reorientou

\footnotetext{
E É ilustrativa a trajetória da primeira economia nacional, a Inglaterra, que em um século aproximadamente de guerras entre a Revolução Gloriosa em 1689 e o fim da era Napoleônica em 18I5, ampliou sua dívida de 17 milhões de libras no começo do período para 800 milhões ao final, sem nunca ter sua credibilidade ameaçada. O que ocorreu com a Inglaterra foi a utilização do seu endividamento como forma de financiar sua expansão, e a expansão fundamentou o pagamento das suas obrigações. Exemplo inverso seriam os países que, ontem e hoje, são forçados a limitar seu gasto e seu endividamento, pelos discursos e pressões das Grandes Potências.

' Para esse ponto, ver Vieira, R.Z. Lembrai-vos da guerra: Ameaça Geopolítica, Organização do Estado e Desenvolvimento Econômico no Pensamento Militar Brasileiro 1913-1964. Dissertação de Mestrado em Economia Política Internacional. Rio de Janeiro: UFRJ, 2014.
} 
o país no sentido de uma política internacional e nuclear autônoma, apoiado em um capitalismo de Estado. A mudança articulada por Geisel entretanto, sucumbiu à oposição externa dos EUA, e interna de parte da elite civil e militar que havia inicialmente apoiado a ditadura.

Como podemos ver, a perspectiva colocada por Fiori inverte muitos padrões de análise, acostumados a se apoiarem na dimensão econômica, e terem como referência algum macroprocesso que contém em si uma grande teleologia. Segundo as teses formuladas em "História, Estratégia e Desenvolvimento", não existe nenhum impulso em direção ao acirramento das contradições do capital e ao socialismo, nem tampouco à racionalidade e eficiência da burocracia isenta e impessoal. Isso, como colocamos, é derivado da própria metafísica do poder utilizada pelo autor. O poder em geral é incapaz de dizer qualquer coisa que sustente uma teleologia, com alguma projeção minimamente palpável de paraíso ou inferno terreno. E o poder concreto é sempre parcial e particular, além de dependente do conflito, sendo, portanto, igualmente incapaz de colocar um fim à história. Aqui chegamos a um ponto interessante: Apesar de se iniciar em uma metafísica, a teoria de Fiori acaba sendo eminentemente histórica, pois só através da história podemos ter algum entendimento útil dos movimentos do poder. E a forma de analisar tais movimentos é tendo como referência inicial o perfil da ameaça sobre o qual o poder articula sua expansão. Dada a ameaça, e o núcleo que a interpreta e formula a estratégia para a sua contenção, podemos chegar às características objetivas, políticas, econômicas, militares e culturais, dos movimentos expansivos dentro do sistema interestatal.

Se ao nível analítico "História, Estratégia e Desenvolvimento" não contém nenhuma teleologia, ao nível político não existe no livro nenhuma grande utopia que possa substituir aquelas que hoje colapsam junto com as teorias do século XIX e início do XX. Ainda assim, podemos identificar nele um caminho a seguir, que passa pela incorporação da geoestratégia como referência fundamental para aqueles que se importam com o destino das nações, e no nosso caso, com os rumos do Brasil. Admitidamente, a geoestratégia não é assunto que anime as massas, mas pode animar as reflexões daqueles estadistas que, entendendo o poder e se preocupando em preservá-lo, acabam inadvertidamente abrindo caminho para a formulação de novas utopias. 
Aqui, o paralelo com o pensador florentino que com seu olhar ao poder subverteu o paradigma católico medieval também é esclarecedor. Há muito se debate, sem que se chegue à qualquer conclusão definitiva, se Maquiavel seria adepto da monarquia ou um republicano de coração. Independentemente da sua preferência nessa questão em particular, o que é relevante é que seu grande sonho era uma Itália centralizada internamente e forte externamente. E essa hierarquia maquiavélica é reflexo não de uma obsessão cínica pelo poder, como pensam muitos, mas de uma compreensão de que, antes de ter uma república ou uma monarquia, era preciso conquistar o poder para instaurar uma ou outra. O mesmo vale para hoje: Antes que possamos formular novas utopias e nos propormos a torna-las realidade, é preciso ter estratégia, porque, nesse sistema, interestatal e capitalista, até para sonhar seus próprios sonhos é preciso ter poder para tanto. 